REVISTA DE DERECHO UNED, NÚM. 11, 2012

\title{
EL EMBRIÓN HUMANO: CONSIDERACIONES ÉTICAS EN CUANTO AL ESTATUTO ONTOLÓGICO DEL MISMO. PROTECCIÓN JURÍDICA
}

\author{
THE HUMAN EMBRYO: ETHICAL CONSIDERATIONS AS FOR \\ THE ONTOLOGICAL ESTATUT OF THE SAME ONE
}

\author{
Gemma Lucía de PaBlos
}

Investigadora del Departamento de Filosofía Jurídica de la UNED

Resumen: Este artículo analiza las distintas vertientes que en relación al concepto de ser humano se da al embrión. Las distintas corrientes éticas y morales, las consideraciones biologías y las genéticas se hayan en relación directa con los distintos grados de protección del embrión. Los distintos estadios y las dificultades reales a la hora de encasillar los diferentes niveles de protección según el desarrollo científico y filosófico, nos permiten una visión real de las posibilidades que se suscitan hoy en día sobre el embrión y su protección, cuya dignidad y entidad ontológica son objeto de debate.

Palabras clave: Embrión, estatuto ontológico, corrientes doctrinales, ciencia, filosofía, ética, moral, dignidad.

Abstract: This article analyzes the different slopes that in relation to the concept of being a human being one gives to the embryo. The different ethical and moral currents, the considerations biologies and the genetic ones are in direct relation by the different degrees of protection of the embryo. The different stadiums and the royal difficulties at the moment of classifying the different levels of protection according to the scientific and philosophical development, allow us a royal vision of the possibilities that are provoked nowadays on the embryo and his protection, which dignity and ontological entity are an object of debate. 
Keywords: Embryo, ontological statute, doctrinal currents, science, philosophy, ethics, moral, dignity.

Recepción original: 16/10/2012

Aceptación original: 19/10/2012

\section{INTRODUCCIÓN}

El inicio de la vida humana y el concepto que esta vida humana tiene en el marco de la sociedad ha sido estudiado desde varios y complejos puntos de vista. Se ha atendiendo a aspectos tanto médicos, como biológicos, como otros muchos de carácter ético e incluso filosófico y jurídico aplicando, mediante la conjunción de todas estas materias, las normas imperantes en las distintas épocas en las cuales este concepto ha sido analizado, para así, dar una definición evolutiva a tal hecho.

Explorando las distintas vertientes objeto de estudio para alcanzar este fin, no podemos obviar la especial responsabilidad que existe por parte de los filósofos y juristas frente a otras ciencias en el momento de plantear los valores, caracteres e incluso derechos existentes desde el inicio de esta vida humana. Surge la imperiosa necesidad, a través del pensamiento, de encontrar un sentido, una base estable que articule con la razón, el conjunto de las características reales y los valores que forman parte del nuevo ser humano, de esta vida humana en desarrollo.

El momento del inicio de la vida humana como tal, la consideración de persona, con los derechos y valores que ello reporta, siempre ha suscitado dudas y en base a las mismas, son las distintas corrientes científicas las que proponen el concepto de ente humano en una u otra etapa de su desarrollo, atendiendo a aspectos genéticos, biológicos y científicos, pero olvidando otros aspectos no menos importantes; es decir, se hace necesario en este punto, atender también a los principios éticos, filosóficos y morales que el concepto de la vida humana, desde el inicio de la misma hasta su completa gestación entraña, no debiendo olvidar el más alto principio ético de la dignidad de la persona, que junto con la propia vida, la libertad o la igualdad, entendido desde la dimensión ética y ontológica, son de necesaria aplicación, para lograr una conjunción correcta entre todas estas corrientes. 


\section{TEORÍAS SOBRE EL ESTATUTO ONTOLÓGICO DEL EMBRIÓN}

La determinación del momento exacto en el cual se produce el inicio de la vida humana, del concepto del ser humano como una persona, con entidad suficiente para focalizar unos derechos inherentes a la propia especie a la cual pertenece ha sido y sigue siendo una de la cuestiones más debatidas en la comunidad científica.

Este planteamiento y por ende su consideración, depende directamente del momento en el que esa nueva vida tiene un estatuto ontológico merecedor de protección.

Se ha de considerar si merece la debida protección y a qué nivel y, en última instancia, cuándo esa nueva vida es equiparable desde un punto de vista jurídico y ético a un ser humano completo y por lo tanto, con carácter inviolable.

El ciclo vital del ser humano se inicia a partir de una célula única denominada cigoto, la cual se crea mediante la fecundación de los gametos femenino y masculino, el óvulo y el espermatozoide respectivamente, que tras un largo y complicado proceso de desarrollo ${ }^{1}$ darán lugar a la formación de un ser humano que producirá en el futuro sus propios gametos, iniciando así un nuevo ciclo en la reproducción sexual humana. A nivel científico existen tres enfoques o tesis en relación a cuando el embrión alcanza el denominado estatus humano, es decir, a través de estas doctrinas se intenta fijar el estadio en el cual, a criterio de los científicos, el conglomerado de células encargadas de la ardua tarea de la procreación humana pueden ser consideradas como ser humano.

La primera de las teorías o corrientes, denominada como teoría de la fecundación o penetración del óvulo por el espermatozoide, se sustenta en que el ovocito fecundado, que da lugar a una célula diploide en el transcurso normal de su desarrollo morfológico, conducirá inexorablemente a la creación de un ser humano completo, por lo que a tenor de esta teoría, la persona humana lo es desde el momento de la fecundación, entendiéndose como tal el proceso biológico por el cual se unen el óvulo y el espermatozoide iniciando así el desarrollo embrionario.

${ }^{1}$ LACADENA, J. R., «Consideraciones genético-biológicas sobre el desarrollo embrionario humano", Genética humana, C. M. ROMEO CASABONA (Ed.), Universidad de Deusto, Fundación BBV, Bilbao, 1995, pp. 77-103. 
Desde el momento de la concepción, el embrión adquiere ya una identidad genética humana y, además es diferenciada frente a los demás individuos, por lo que, según este sector doctrinal, nos encontramos ante un ser humano digno de protección. Esta teoría es muy similar a la denominada teoría de la singamía, en la que la fusión de los gametos masculino y femenino da lugar al ovocito pro-nucleado, el cual posteriormente crea el cigoto, restableciéndose así el número diploide de cromosomas por lo que puede sostenerse que a partir de este momento estamos en presencia de vida humana, ante la existencia de un ser humano cuyo desarrollo se va a realizar de acuerdo con su propio programa genético, del cual dependerá el futuro aspecto morfológico y morfogenético en cada momento de su vida.

Hemos de tener en cuenta que el estatuto moral que en dicha corriente doctrinal o teoría se postula es predicable a cualquier cigoto humano, con independencia de que éste haya sido fecundado de manera natural o de forma artificial mediante técnicas de reproducción médica asistida. No podemos olvidar que la fecundación es la fase de desarrollo embrionario que determina la adquisición de personalidad jurídica y por ende, la titularidad del derecho a la vida por parte del no nacido, cuyo pleno disfrute no puede ser interrumpido. Por ello, el uso de las nuevas técnicas de reproducción humana son, para esta corriente doctrinal, plenamente compatibles con el respeto a la vida del embrión, con la salvedad de que dichas técnicas no sean utilizadas para fecundar un número mayor de cigotos de los que van a ser implantados en el útero materno en cada tratamiento de fertilidad ${ }^{2}$.

La segunda de las teorías, llamada la teoría de la anidación parte del supuesto de que en el instante en que el embrión humano se implanta en la pared interna del útero, fenómeno que se produce alrededor de los catorce días posteriores a la fusión de los núcleos de los gametos, se produce un hito embriológico sumamente importante: es en ese preciso momento cuando se da inicio a la existencia individualizada de un nuevo ser humano. Aquellos que sostienen esta tesis argumentan que en los estadios anteriores a la anidación nos encontramos ante un conjunto de células indiferenciadas que, sin embargo, poseen la capacidad de desarrollarse hasta formar un ser humano cuyo comienzo se efectúa con la anidación, la implantación del embrión en el útero materno, siendo este momento el inicio de una nueva forma de vida humana.

${ }^{2}$ ROMEO CASABONA, C. M., «La utilización de embriones y fetos humanos con fines en la investigación genética y otros fines no terapéuticos», Cuadernos del instituto Vasco de Criminología, núm. 5, 1992, pp. 151-158. 
Así pues, para esta corriente doctrinal, la vida de los embriones uterinos de más de catorce días en desarrollo es digna del mismo grado de protección que la de las personas que ya han nacido, sin que pueda ser interrumpida esta vida mediante intervenciones que tengan como objeto la investigación científica del embrión en dicha fase o mediante cualquier otra intervención. En el caso de aquellos ovocitos que sean fecundados de manera artificial y que cuenten con menos de 14 días y cuando los mismos no sean implantados en el útero materno no se los trataría como sujetos pertenecientes a la especie humana, solo única y exclusivamente a partir del instante en el que adquieran el status moral de persona mediante su implantación en el útero materno correspondiente.

En tercer y ultimo lugar tenemos la teoría de la formación del sistema nervioso central o cresta neural, que entiende que con la aparición de la llamada línea primitiva o surco neural en el embrión, lo que luego será la corteza cerebral que se forma a partir de la sexta semana de gestación a contar desde la fecha en la cual se produjo la concepción, se adquiere el estatus de persona.

Aquellos que aceptan esta corriente afirman que este tejido orgánico determina la capacidad del embrión para sentir e interactuar mediante impulsos eléctricos cerebrales verificables, adquiriendo consciencia $\mathrm{y}$, por lo tanto, puede afirmarse la existencia de una persona en proceso de formación tanto desde un punto de vista moral como clínico-sanitario. El desarrollo de esta actividad neuronal consciente se produce a partir del tercer mes desde la fecha de la concepción, momento en el que el embrión se asemeja físicamente a un ser humano adulto, por lo cual el estatuto de ser humano se haya implícito, demostrándose incluso por la propia variación en lo que a la denominación científica de los términos se refieren cuando se pasa del termino de embrión al de feto.

Esta capacidad sensitiva y, por ende, la apariencia humana del feto se constituyen en evidencias objetivas de la existencia moral de la persona cuya vida merece el mismo grado de protección jurídica que la de los concebidos y ya nacidos. En el caso de los embriones fecundados in vitro, este sector doctrinal considera que, en tanto en cuanto éstos no van a ser empleados con fines reproductivos, no pueden ostentan el estatuto moral de personas, ya que sin el desarrollo necesario no pueden efectuar ningún tipo de actividad neuronal autónoma, consciente ni independiente, por lo que estos cigotos tan sólo son complejos celulares, en mayor o menor grado, que pueden ser usados en la experimentación científica hasta la sexta, o en su 
caso, duodécima semana de desarrollo a tenor de las normativas existentes al respecto.

\section{ASPECTOS ÉTICOS Y MORALES}

Todas y cada una de las tesis aquí expuestas parten de unos datos científicos que, en todo caso, son necesarios considerar para poder debatir con exactitud los aspectos éticos y morales que corresponden al embrión humano, sea éste creado de forma natural o a través de las actuales técnicas de reproducción humana. El conocimiento de ciertas premisas científicas nos hará adecuar los aspectos filosóficos que son inherentes al embrión humano teniendo en cuenta la necesidad de ciertos criterios jurídicos para evitar la posible vulneración de la dignidad de la persona humana.

En este sentido hay que recordar que la fecundación no es un instante, sino que es un proceso biológico constante y continuado en el tiempo y que la activación del óvulo por el espermatozoide es anterior a la identidad genética, que no se logra hasta la completa formación del núcleo diploide.

El principal problema radica en el momento ontólogico ${ }^{3}$ en el cual el embrión, antes de la anidación, denominado como preembrión, o después de la misma, puede ser considerado como ser humano. Si atendemos al antiguo concepto filosófico de persona efectuado por Severino Boecio ${ }^{4}$, que lo definía como «la sustancia individual de naturaleza racional»; es decir, la definición dada en estos momentos señalaba ya la necesaria racionalidad del individuo en base al concepto de ser único, autónomo e individual, aspectos éstos que han sido tratados posteriormente por otros autores ${ }^{5}$.

Estas características o propiedades sin embargo no se establecen en el embrión no implantado puesto que el concepto clásico de persona resultaría en este caso inaplicable. Sin embargo, para algunos autores, aun admitiendo estos datos, consideran que el pre-embrión, aquel aun no anidado, no deja por ello de tener un altísimo valor, debido a que tiene en su origen identidad humana y, por lo tanto, un elevado potencial de convertirse en persona. La cuestión por lo tanto radicaría

${ }^{3}$ DE CASTRO CID, B., «Los dos planos del saber: el ontológico y el plano crítico o epistemológico», en DE CASTRO, B. (ed). 18 lecciones de filosofía del derecho, UNEDUNIVERSIDAD, Madrid, 2008, pp. 21-34.

${ }^{4}$ Filósofo del último periodo romano perteneciente a la escuela del neoplatonismo.

${ }^{5}$ GRACIA, D., Fundamentos de bioética, Eudema, Madrid, 1989, p. 121. 
en delimitar qué estatuto asignarle y en qué fase de su desarrollo posee todos los derechos adscritos a la persona humana adulta ${ }^{6}$.

Muchos de los defensores de la inviolabilidad del embrión se centran en la idea de que el embrión tiene potencialidad de convertirse en persona. Potencialidad basada en primer lugar, en la «capacidad informacional», que implica toda la información que puede dirigir el desarrollo de un ser humano; y en segundo lugar, el «contenido informacional», el cual se debe considerar como toda la información que se puede usar para desarrollar al ser humano, aunque no esté disponible en un determinado momento para hacerlo. Sin la existencia de estas cualidades no podemos hablar de dignidad de la persona y más cuando nos referimos a células que carecen de la información suficiente, siendo entre la sexta y la octava semana cuando el sistema ya se ha desarrollado y el embrión debe tener un estatuto equiparable con el de un ser humano adulto.

Algunos filósofos como Xabier Zubiri mantuvieron durante cierto tiempo que la psique humana es una nota constitutiva, afirmando que la realidad humana ha sido dotada desde el principio de dichas notas mediante el genoma y la psique, las cuales tendrían desde este inicio personeidad ${ }^{7}$; sin embargo, posteriormente dicho autor consideró que el psiquismo surge desde las estructuras materiales como consecuencia del propio proceso constituyente, abandonando su anterior teoría e indicándonos que es necesaria una cierta complejidad celular por lo que el psiquismo humano no sería una nota constitutiva para el término sino un resultado estructural durante la constitución de la sustantividad.

La sustantividad real del ser humano viene establecida genéticamente por su fenotipo, del que el genoma es un subsistema sustanti$v^{8}$. El genoma tiene notas constitutivas, pero sin embargo carece en si mismo y en origen de de sustantividad, es lo que a tenor de estas corrientes consideramos una esencia no autosuficiente del sistema por lo que genéticamente se debe considerar el genoma desde el fenoma, y no al revés.

${ }^{6}$ DE CASTRO CID, B., «Biotecnología y Derechos Humanos: ¿complementariedad o conflicto?», Aldaba, núm. 32, Madrid, 2004, pp. 13-30.

${ }^{7}$ ZUBIRI APALATEGUI, X., El hombre y la verdad, Alianza Editorial, Madrid, 1999, pp. 46-60 y 257.

8 JUNQUERA DE ESTEFANI, R., «Interrogantes planteados por la manipulación genética y el proyecto genoma humano a la filosófica jurídica», Anuario de Filosofía de Derecho, vol. 20, Madrid, 2003, pp. 165-168. 
El desarrollo de un ser humano no depende única y exclusivamente de los genes, sino de la compleja interacción entre éstos y el citoplasma; de la propia información posicional de células; del entorno materno, etc. Por ello la sustantividad humana no se crea con el mero hecho del acto de la fecundación, sino que la misma es un proceso epigenético que necesita un tiempo y un espacio propio.

El cigoto no es una sustancia completa en la que casi todo está en potencia, ya que realmente no hay sustancias completas dotadas de finalidad interna, es decir, las cosas no son completas al principio ni están dotadas de finalidad intrínseca, filosóficamente hablando. Recordemos en este punto la teoría de las cuatro causas efectuada por Aristóteles y la dependencia del concepto de telos o fin.

Aristóteles empleaba la palabra causa en el sentido de explicación de las cosas a considerar para conseguir entender un objeto o proceso en su totalidad, daba cuenta en su filosofía de todos los factores que deben ser considerados para llegar a entender un ente, sea este ente natural o artificial, definido en cuatro clases; el primer grupo, dividido en material y formal, siendo estos aspectos internos intrínsecos al ente; y el segundo, el eficiente y final, aspectos externos al ente $^{9}$. La causa material define de lo que están hechas las cosas, un ejemplo citado usualmente es la madera, la cual es la causa material de un árbol. La causa formal se define como aquello que da a cada cosa su forma determinada, el tipo o esencia, por ejemplo, el árbol es la causa formal. La causa eficiente es aquella que explica el paso de potencia a acto, es decir, la materia no pasa al acto por sí misma, no puede producir una determinación nueva si no recibe un influjo que haga surgir lo que tiene en potencia, la causa eficiente es aquello por lo que algo acontece, el antecedente que provoca un cambio, el principio inmediato del movimiento, y a su vez, una causa eficiente no puede producir cualquier cosa, sino que es la causa final de aquello para lo que todo el resto se organiza, la finalidad determinada. La causa final siempre se encuentra en la naturaleza, es el fin natural inmanente de las cosas.

Tras algunas contradicciones cuestionadas por diversos autores respecto del argumento planteado por Aristóteles, no existe hoy un consenso en cuanto al uso exacto del lenguaje teleológico-filosófico en las explicaciones biológicas. Según los planteamientos hoy aducidos, no se puede por lo tanto hablar de potencialidades hasta que la nueva realidad está constituida, realidad que según las teorías enun-

9 JIMÉNEZ, F., "Lecciones sobre Aristóteles», Cuadernos de Filosofía del IES, Ponencias Febrero, Madrid, 2009, pp. 25-30. 
ciadas al principio del presente punto, dependerán del momento en el cual aceptemos la existencia de un patrimonio genético constituido que de lugar al nuevo ser humano, con suficiencia constitucional y sustantividad.

Sectores liberales se encuentran a favor del pleno estatuto moral del embrión en tanto en cuanto afirman que todo ente biológico es un individuo cuando es un organismo, es decir, una unidad integrada por estructuras y funciones, cualquiera que sea su grado de complejidad. Sin embargo, en filosofía ser individuo es lo opuesto a ser género, tal y como en este sentido planteó Roberto Andorno ${ }^{10}$, en cuanto el individuo subsiste como tal y como individuo se distingue de otra realidad. Aunque no pueda demostrarse de modo fehaciente la personalidad del embrión humano, existen importantes razones para atribuirle el respeto que se debe a las personas: la razón es que de alguna manera somos un cuerpo viviente y este cuerpo ya comienza a existir en el estadio embrionario, nuestra dimensión corporal debe ser considerada como elemento constitutivo de nuestro ser personal.

Si bien es cierto que podemos discernir diferentes fases en el desarrollo humano en las que podemos hablar de una unicidad genética, de una continuidad biológica y de una autonomía en el desarrollo del embrión, éste a su vez tiene una capacidad activa extraordinaria para desarrollarse y para controlar y coordinar las diversas etapas de su proceso de formación; no es menos cierto que, por ello, no debemos de crear compartimentos estancos con diferentes niveles ontológicos, calificando al ser humano en función de la fase de desarrollo. Una vez que se inicia éste, el establecer una frontera para comenzar en un determinado momento su protección como persona humana, éticamente implicaría una selección arbitraria por parte de aquellos que efectúan tal división, respecto a los que la sufren y no pueden efectuar alegación alguna ${ }^{11}$. Otras posturas plantean respetar al embrión en base al principio «in dubio, pro embryo».

Según esta corriente, debemos abandonar la pretensión de valorar la esencia humana para evitar una consideración meramente moral del ser en desarrollo, lo que en definitiva propiciaría convertir a los embriones no en una entidad con interés y valor intrínseco,

${ }^{10}$ ANDORNO, R., «La dimensión biológica de la dignidad humana: el debate sobre el estatuto del embrión», Cuadernos de Bioética, vol. 15, núm. 53, Madrid, 2004, pp. 29-36.

${ }^{11}$ DE MIGUEL BERIAIN, I., “¿Es digno un ser que no es autónomo?», Estudios en homenaje al Prof. Peces-Barba, vol. 3, 2008, pp. 415-430. 
sino en un ente dotado de posibilidades para los intereses, objetivos y utilidades científico-comerciales ${ }^{12}$.

\section{LA DIGNIDAD DEL EMBRIÓN HUMANO}

La dignidad humana es la cualidad esencial del ser humano que es específica en el mismo y de carácter exclusivo, pudiendo distinguirse en base a esta dignidad lo humano de lo no humano ${ }^{13}$. La dignidad se establece como una seña de identidad en el ser humano, como ser dotado de inteligencia y libertad, como ser moral, siendo esta dignidad un valor fundamental del cual emanan otros valores ${ }^{14}$, que se constituyen en dimensiones básicas de la persona y además determinan la existencia y legitimidad de todos los derechos que se hallan reconocidos en el ordenamiento jurídico ${ }^{15}$.

Por otra parte, estos valores están indisolublemente unidos por su raíz y fundamento al valor de la dignidad de la persona que se sitúa antes que ellos, constituyendo el ser humano un prius lógico y ontólogico de los mismos ${ }^{16}$, de ahí que la legitimidad y fundamento de un derecho concreto tenga su base en la dignidad humana, que es la justificación del reconocimiento de los derechos.

Kant configura la expresión de la idea de la dignidad humana como categoría ética, vinculada a la dimensión moral del hombre, afirmando ${ }^{17}$ que: "...Los seres cuya existencia no descansa en nuestra voluntad, sino en la naturaleza, tienen, cuando se trata de seres irracionales, un valor puramente relativo, como medios, y por eso se llaman cosas; en cambio los seres racionales se llaman personas porque su naturaleza los distingue ya como fines en sí mismos, esto es, como algo que no puede ser usado como medio y, por tanto, limita, en este sentido, todo capricho... son fines objetivos, esto es, realidades cuya existencia es en sí misma, un fin...». Kant consideró la autonomía

${ }^{12}$ SINGER, P., Repensar la vida y la muerte. El derrumbe de nuestra ética tradicional, Paidós, 1997, Barcelona, pp. 207-214.

${ }^{13}$ DE MIGUEL BERIAIN, I., "La Dignidad Humana. Fundamento del Derecho», Boletín de la Facultad de derecho de la UNED, núm 15, Madrid, 2007, pp. 325-356.

${ }^{14}$ DE MIGUEL BERIAIN, I., "Consideraciones sobre el concepto de Dignidad humana», núm. 21, Madrid, 2004, pp. 187-212.

15 JUNQUERA DE ESTEFANI, R., Algunas cuestiones de Bioética y su Regulación Jurídica, Grupo Nacional de Editores, Sevilla. 2004, pp. 87-104.

${ }^{16}$ MARCOS DEL CANO, A. M., Bioética, Filosófica y Derecho, UNED, Melilla, 2004, pp. 165-206.

${ }^{17}$ KANT, I., Fundamentación de la metafísica de las costumbres, Espasa, Calpe, 2008, p. 19. 
personal como rasgo humano y en tal contexto nos habla de la «dignidad de un ser racional que no obedece otra ley que aquella que se da así mismo.» Por lo tanto, la concepción de la moralidad ${ }^{18}$ es una de las condiciones bajo la cual un ser racional puede ser fin en sí mismo, por que él mismo es legislador de los fines.

En el debate bioético contemporáneo, la dignidad del ser humano radica en la individualidad original y única que todo embrión posee, por lo que si no hay un respeto y defensa por la corporalidad humana desde el primer momento de su aparición, es imposible afirmar la dignidad de cualquier ser humano ${ }^{19}$. La dignidad humana corresponde, desde el plano ontológico, a cada uno de los seres humanos. El hombre es digno por lo que es. Su excelencia radica en su ser humano, ya que no se es más o menos digno dependiendo del cumplimiento de una serie de requisitos o características, de este modo, el hombre puede ser considerado un ser querido por sí mismo, es la dignidad ontológica. Esta dignidad es la misma para todos en cuanto se descubre en el hombre por el sólo hecho de existir, por el hecho exclusivo de ser hombre. La dignidad ontológica por tanto tiene su origen en el hombre y acompaña necesariamente a todo ser humano por el sólo hecho de serlo.

La dignidad de los seres humanos está en la base de todos los valores humanos, pero ella misma no es un valor, de no ser así, la dignidad del ser humano y su derecho a la vida se convierten en objeto de ponderación respecto de otro valor, que en un posible conflicto de valores, esa dignidad puede ser pospuesta por otro valor.

El planteamiento kantiano como paradigma de la dignidad entendida como autonomía moral se constituye independientemente de cualquier referencia a la naturaleza humana entendida ésta como pura ciencia empírica, sin embargo, el concepto ontológico de la idea de dignidad permite diferenciar claramente ambas dimensiones, porque su punto de partida no lo constituye la libertad como autonomía, sino el análisis mismo de la naturaleza humana como un tipo de naturaleza peculiar. Por eso, desde una concepción teleológica de la naturaleza en la que la persona se reconoce en su corporalidad, el concepto de dignidad es operativo.

Desde una concepción teleológica de la naturaleza, la dignidad de la persona se manifiesta en la corporalidad de un hombre concreto desde

18 SANZ FERRAMOLA, R., "El imperativo categórico de Kant en Freud», Fundamentos en Humanidades, núm. 3, Madrid, 2001, pp. 167-187.

${ }^{19}$ ZURRIARAIN, R., "La dignidad del embrión humano», Revista de Medicina, vol. 51, núm.1, pp. 30-32. 
su concepción hasta su muerte, ya que lo corporal no le viene a la persona desde fuera, como un complemento del que se puede prescindir o un elemento que no lo defina, sino que le es intrínseco al mismo, no es una cosa externa a la persona y la relación con su cuerpo no es la misma que se tiene con las cosas: el cuerpo humano es el hombre mismo.

Este dualismo antropológico entre lo racional y lo natural en el hombre se traslada al ámbito de las ciencias de la vida: si la dignidad del ser humano reside exclusivamente en su racionalidad y libertad, entonces su dimensión corporal queda reducida al ámbito de lo meramente físico, lo empírico, lo biológico, aspectos que no forman parte esencial de la definición de ser humano ${ }^{20}$. Bajo este prisma, el embrión humano no es un ser que deba ser respetado desde el inicio, pues carece de dignidad al reducir ésta a su autonomía que aparece con el desarrollo embrionario del mismo tras la aparición de las primeras funciones racionales. Hasta ese momento su realidad ontológica no es la de un "alguien», sino la de un «algo» que la naturaleza ha producido denominado preembrión o material biológico humano, del cual podemos disponer para otros fines.

Resulta entonces que, la posibilidad de dar un estatuto ontológico adecuado al embrión pasa por un concepto teleológico de naturaleza. La dignidad humana sólo tiene sentido si se reconoce a todo ser biológicamente humano por el hecho de ser humano y no si es conferida en atención a ciertas propiedades más o menos esencia$\operatorname{les}^{21}$. Las personas no se definen, se reconocen. Esta argumentación evita que cualquier ser humano se convierta en juez para decidir si otro individuo humano posee o no los rasgos fundamentales de una persona o si es o no un sujeto de derechos. Desde esta segunda postura la noción de derechos humanos quedaría suprimida de raíz puesto que si hay derechos humanos, el primero de ellos radicará en que nadie tenga la potestad para decidir si otro posee la categoría de persona, sino que su pertenencia a la especie humana sea suficiente para que sea considerada sujeto de derechos.

El hombre es digno porque es, no porque lo sabe o siente, sino que su excelencia radica en su ser. Dignos son cada uno de los seres humanos concretos que realiza la especie a la que pertenece de un modo original, único e irrepetible, de tal modo que los seres humanos compartimos una igualdad fundamental, una igualdad de naturaleza,

${ }^{20}$ GONZALEZ, A., "Naturaleza y Dignidad. Un estudio desde Robert Spaemann», Eunsa, Pamplona, 1996, p. 69.

${ }^{21}$ PALAZANNI, L., "El concepto de persona en el debate bioético y biojurídico actual», Medicina y ética, vol. 1, 1997, pp. 31. 
que sería criterio suficiente para que todo ser humano fuese respetado desde su concepción. Esta unidad ontológica, que hace posible todo el proceso de desarrollo de una individualidad única, antes y después del nacimiento, científicamente denominada como la unidad biológica del embrión, constituye también el fundamento del reconocimiento de la dignidad humana desde el primer momento de su existencia.

\section{PROTECCIÓN DE LOS EMBRIONES}

Ley Orgánica 9/1985 de 5 de julio introdujo el articulo 417 bis en el Código Penal Español, mediante el cual se despenalizaba parcialmente el aborto. Posteriormente, el Real Decreto de 21 de noviembre 2409/1986 se crea para precisar y facilitar el estricto cumplimiento de los requisitos legales y sanitarios exigibles en los casos y circunstancias establecidos en la Ley 9/1985, ya que es la sentencia del Tribunal Constitucional 53/1985 de 11 de abril, relativa a la constitucionalidad de la ley despenalizadora del aborto en determinados supuestos, la que exige, entre otros aspectos, la comprobación del supuesto de hecho en los casos de aborto terapéutico y eugenésico, así como que el aborto se realice en centros sanitarios, públicos o privados autorizados al efecto; de ahí la necesidad de adecuación de la estructura asistencial y sanitaria.

Dicha sentencia trata también del derecho a la vida, reconocido y garantizado en su doble significación física y moral por el propio articulo 15 de la Constitución Española, siendo la proyección de un valor superior del ordenamiento jurídico constitucional un derecho fundamental, esencial y troncal en cuanto es el supuesto ontológico sin el que los restantes derechos no tendrían existencia posible, relacionándolo de forma directa con la dignidad de la persona como núcleo de unos derechos que le son inherentes.

Se plantean los deberes positivos por parte del Estado, quien debe garantizar un sistema de valores que sean el fundamento del orden jurídico y de la paz social, obligando especialmente al legislador a establecer supuestos para su defensa.

A tenor de este valor, es el Estado el que tiene la obligación de abstenerse de interrumpir el proceso natural de gestación y de establecer un sistema legal para la defensa de la vida que suponga una protección efectiva de la misma dado su carácter fundamental.

La condición de bien jurídico constitucional que se reconoce a la vida fetal obliga al Estado a concederle una tutela jurídica adecuada 
que en alguna medida, alcanza al derecho penal, lo que no significa que la vía penal deba ser la única forma de tutela, ni siquiera la preferente, lo esencial es que del ordenamiento jurídico en su conjunto, incluido el ámbito punitivo, pueda inferirse con claridad una política pública dirigida a asegurar el respeto de la vida en gestación.

Urge por lo tanto, una legislación que proteja al ser humano desde el inicio de su vida y a la madre gestante. Esta legislación sí haría justicia con el no nacido y su madre, sólo así, el aborto dejaría de ser una decisión de la mujer en el mayor de los aislamientos para convertirse en una elección informada, formada y libre. De igual manera, y en lo que respecta a las técnicas de reproducción asistida y la actual investigación biomédica, las actuales normativas han creado ciertas inseguridades jurídicas en concreto en cuanto al aborto, respecto de las cuales es necesario tratar y precisar términos concretos.

Recordemos que el estatuto jurídico del «nasciturus» es un bien jurídicamente protegido y no como un ser humano con la misma dignidad humana que el ya nacido, es como materia susceptible de utilizarse como un medio para investigar en el ámbito biomédico.

Esta respuesta depende directamente de las teorías biológicas sobre los orígenes de la vida, son los científicos los que deben proporcionar los datos necesarios para saber si hay vida humana o no desde ese momento de la fecundación, siendo hoy mayormente aceptada la teoría de la anidación.

\section{CONCLUSIONES}

A tenor de lo expuesto, lo que necesitamos y se hace realmente necesario en la actualidad es un tipo de consenso filosófico, ético y legal para establecer una línea divisoria a partir de la cual el ser humano en desarrollo adquiera irreversiblemente el estatuto merecedor de protección como persona, como ser humano, sin olvidar que la insistencia de dar valor moral a todo lo humano en función de su contexto y de valores externos adjudicados por otras personas no puede conducir más que a una inseguridad legal y a una sociedad que sólo protege a aquellos que pueden levantar su voz o que puedan decir de sí mismos que son personas.

Quizás y sólo quizás, fuera necesario, ante los actuales avances técnicos y científicos retomar ciertas posturas filosóficas como el esencialismo aristotélico, para en base al concepto de la dignidad humana, aclarar el estatuto moral de las fases prenatales y neonatales del ser humano con el objetivo de asegurar el bien futuro. 